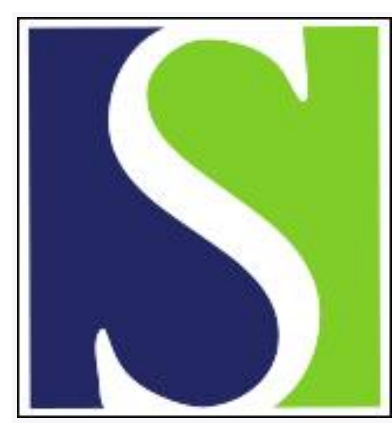

Scand J Work Environ Health 1992;18(4):262-268

https://doi.org/10.5271/sjweh.1579

Issue date: 01 Aug 1992

Electromyographic signs of shoulder muscle fatigue in repetitive arm work paced by the Methods-Time Measurement system.

by Sundelin G, Hagberg M

Affiliation: National Institute of Occupational Health, Division of Occupational Medicine, Umea, Sweden.

This article in PubMed: www.ncbi.nlm.nih.gov/pubmed/1411370

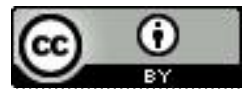




\title{
Electromyographic signs of shoulder muscle fatigue in repetitive arm work paced by the Methods-Time Measurement system
}

\author{
by Gunnevi Sundelin, $\mathrm{PhD}^{1,2,3}$ Mats Hagberg, $\mathrm{MD}^{4,5}$ \\ SUNDELIN G, HAGBERG M. Electromyographic signs of shoulder muscle fatigue in repetitive arm work \\ paced by the Methods-Time Measurement system. Scand J Work Environ Health 1992;18:262-8. Sur- \\ face electromyographic (EMG) recordings from the lateral and cervical portions of the descending trapezius \\ muscle and from the infraspinatus muscle were assessed for six female subjects performing a standardized \\ repetitive work simulation task for $1 \mathrm{~h}$. The work pace was determined according to the Methods-Time \\ Measurement system to 2466 cycles $\cdot \mathrm{h}^{-1}$. The variation in load levels were high and indicated dynamic \\ muscle activity. A decrease in the EMG mean power frequency and an increase in the root-mean-square \\ amplitudes, both indicating muscle fatigue, developed in all muscles of most of the subjects. EMG signs \\ of fatigue, analyzed separately for each 5 -min period, showed variable fatigue patterns both between muscles \\ and between subjects. It is therefore suggested that dynamic work movements do not protect the muscles \\ of the shoulder and neck from fatiguing processes in highly repetitive work with short cycle times.
}

Key terms: neck, repetitive work cycle, shoulder, work organization.

It has been suggested that static work postures and repetitive arm movements are important factors in the development of work-related symptoms from the shoulder and neck $(1,2)$. Muscle fatigue could be one factor in the development of neck and shoulder discomfort in repetitive work tasks. In vocational studies muscle fatigue has often been analyzed with electromyographic (EMG) amplitude and spectral analysis $(3-10)$.

In a repetitive work task (eg, in assembly work) the work pace is usually not self-chosen, and the worker must follow a predetermined pace. From the point of view of work physiology information on the optimal work pace with which to avoid muscle fatigue and discomfort is scarce. A motion analysis system widely used for calculating work pace is the Methods-Time Measurement (MTM) system $(11,12)$. According to this system it is possible to calculate the number of work cycles exactly, while paying minor attention to work posture. In this study much emphasis was been placed on a standardized workstation, work posture, and work pace.

\footnotetext{
${ }^{1}$ National Institute of Occupational Health, Division of Occupational Medicine, Umeá, Sweden.

2 Department of Occupational Medicine, University Hospital, Umeá, Sweden.

${ }^{3}$ Department of Anatomy, University of Umeå, Sweden.

4 National Institute of Occupational Health, Division of Work and Environmental Physiology, Solna, Sweden.

$s$ Department of Occupational Health, Karolinska Hospital, Stockholm, Sweden.
}

Reprint requests to: Ms G Sundelin, National Institute of Occupational Health, Medical Division, Box 7654, S-907 13 Umeá, Sweden.
The objective of this study was to investigate whether fatigue indicated by changes in EMG amplitude and spectral variables develops in shoulder and neck muscles in MTM-paced work.

\section{Subjects and methods}

\section{Subjects}

Six healthy female physiotherapy students volunteered to participate in the study. Their mean age, height, and weight were 26.3 (SD 5.57) years, 168.8 (SD 5.88) cm, and 64.8 (SD 9.26) kg, respectively. All of the subjects were right-handed and participated in physical activities once or twice a week. The methods were approved by the Ethical Committee of the University of Umeå.

\section{Work task}

In a controlled laboratory setting the subjects performed repetitive arm work continually for $1 \mathrm{~h}$. The work consisted of grasping a small cylinder with the right hand and then releasing it through a hole in a table (figure 1). Posture was adjusted so that each subject was seated with 90 degrees of flexion at the hips and knees with the height of the table level to the elbow when relaxed. The subjects were not allowed to speak, and a black curtain was placed in front of them to avoid any distractions during the work simulation task.

\section{Work pace}

The work pace was determined according to the MTM system as follows. A box filled with small cylinders (22 $\mathrm{mm}$ in diameter, $70 \mathrm{~mm}$ in height, $15 \mathrm{~g}$ in weight) 
was placed $40 \mathrm{~cm}$ away from the subject and slightly to the right. When grasping the cylinder, the subject flexed the shoulder to 90 degrees. The work cycle consisted of the following four components in transferring the cylinder: (i) reaching, (ii) grasping, (iii) moving, and (iv) releasing. According to the MTM system, time measurement units (TM units) can be assigned for the four motion components from MTM tables. From 44.6 TM units, calculated for the work cycle being used in our study, a basic pace of MTM-100 was calculated. In this study, however, we chose a work pace according to MTM-110 since assembly work in Sweden is often paced between MTM-110 and MTM-120. We thus multiplied the work pace according to MTM-100, 2242 cycles, by 1.1 and determined the pace to be 2466 cycles $\cdot \mathrm{h}^{-1}$ (ie, 41 cycles $\cdot \mathrm{min}^{-1}$ ) with each cycle lasting $1.46 \mathrm{~s}$. This work pace was indicated by an audiovisual signal. The day before the experiment started, each subject had a short period of training to get used to the work pace, and thus no one had difficulties in following the predetermined speed. The subjects were relaxed physically and mentally when they started the work simulation task. All of the experiments were performed in the afternoon.

\section{Electromyography}

The EMG activity was recorded by surface electrodes on the right side from the lateral and cervical portions of the descending trapezius muscle and from the infraspinatus muscle. Bipolar surface silver-silver electrodes were used with a contact diameter of $6 \mathrm{~mm}$ and an interelectrode distance of $2 \mathrm{~cm}$ for the cervical portion of the trapezius muscle and $3 \mathrm{~cm}$ for both the lateral portion of the trapezius muscle and the infraspinatus muscle. Small Medinik ${ }^{\circledR}$ amplifiers were used for linear amplifications of the EMG signals with a bandwidth of $5-500 \mathrm{~Hz}$. The amplified signals were recorded on a frequency-modulated tape recorder (Teac R 71) with a bandwidth of direct current to $1250 \mathrm{~Hz}$.

Before the EMG measurements, the maximal elevation strength and the external rotation strength of the right shoulder were measured with a strain gauge dynamometer with simultaneous EMG recording. The maximal elevation strength and external rotation strength were used as reference voluntary contractions (RVC) in order to obtain the relationship between force and the EMG result during the repetitive work. The best of three attempts was regarded as a subject's maximal reference value. The measurement procedure has been described in more detail in previous studies on word-processor operators $(13,14)$.

\section{Analysis of surface electromyography}

The analysis of the EMG signals was made on a super microcomputer. The signals were converted from analogue to digital at a sampling frequency of $4 \mathrm{kHz}$ for each channel with 12-bit accuracy over the signal range of $\pm 5 \mathrm{~V}$. The fast fourier transform technique was used to obtain the power spectral density function for an average time of $250 \mathrm{~ms}$ with a bandwidth of $10-500 \mathrm{~Hz}$.

The mean power frequency (MPF) and root-meansquare (rms) values of the amplitudes were computed in parallel processes for the entire work period of $1 \mathrm{~h}$ and separately for each 5 -min period. One mean value for both the MPF and the rms was calculated for each second per subject. The entire work period consisted thus of 3600 samples, and the 5-min periods of 300 samples. In a simultaneous analysis of MPF and rms regression versus time it was possible, on the basis of the slope coefficient, to create nine different combinations of changes in surface signal characteristics in which the MPF and rms values can either increase, be unchanged, or decrease (15). In accordance with the literature on surface EMG analysis $(4,5,8,9,16,17)$, we considered an increase in rms and a decrease in MPF as an electrophysiological sign of muscle fatigue. Other possible combinations of rms and MPF could reflect recovery, increased or decreased muscle performance, or temperature changes (15). In this study the focus was, however, only on muscle fatigue.

In computing the rms amplitude analysis, we used the EMG force relationship in reverse in order to transform the myoelectric activity during the repetitive work to a force expressed as the percentage of the RVC. The amplitude probability distribution function, according to Ericson \& Hagberg (18) and Hagberg (19), was computed for the detected rms signal.

\section{Rating of perceived exertion}

Borg's RPE scale (20) for the rating of perceived exertion (RPE) was used every fifth minute during the work simulation task.

\section{Statistics}

Regression analysis was performed for the analysis of changes in the MPF and rms with time as the independent variable and MPF and rms as dependent variables. Regression analysis was performed over the entire work period of $1 \mathrm{~h}$ and for each 5 -min period. Intercept, slope, and $95 \%$ confidence intervals were calculated. In the amplitude probability distribution func-

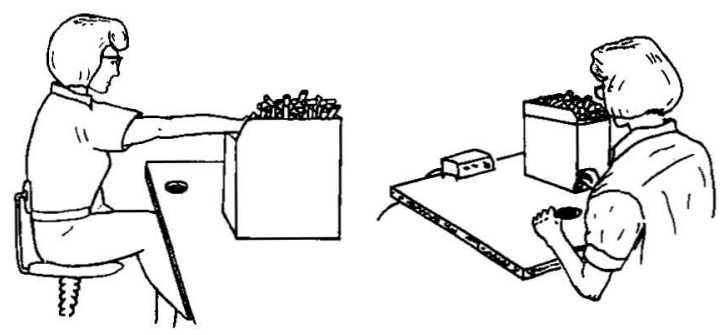

Figure 1. Experimental set-up during the $1 \mathrm{~h}$ of repetitive work. 
tion, statistical procedures according to Hagberg (19) and Ericson \& Hagberg (18) were used. Pearson's product moment correlation was calculated for concurrence between the mean of the MPF and rms versus the RPE for each 5-min period.

\section{Results}

\section{Muscle load}

There was much variation in muscle activity during the simulated work task, as illustrated by the difference between the peak and the static muscle load. For the lateral portion of the descending trapezius muscle the median value for the peak load was $31 \%$ of the RVC, and for the static load it was $4.4 \%$. The variation in RVC was $37-17 \%$ for the cervical portion of the descending trapezius muscle and $55-12 \%$ for the infraspinatus muscle for peak and static load, respectively.

\section{Muscle fatigue during the entire work period}

The regression analysis of the EMG amplitude and frequency versus time for the lateral portion of the descending trapezius muscle showed signs of fatigue by negative slopes for the MPF and positive slopes for the rms of all of the subjects (table 1). For the infraspinatus muscle the slopes of the MPF values were negative for all six subjects. The slopes of the rms were

Table 1. Regression analysis of the mean power frequency (MPF) (Hz) and root-mean-square (rms) amplitudes ( $\mu$ V), versus time (s), for the lateral portion of the descending trapezius muscle. The intercept, slope, and $95 \%$ confidence interval for the slope coefficient are illustrated for each subject.

\begin{tabular}{|c|c|c|c|c|c|c|}
\hline \multirow[b]{2}{*}{ Subject } & \multicolumn{3}{|c|}{ MPF } & \multicolumn{3}{|c|}{ rms } \\
\hline & Intercept & $\begin{array}{c}\text { Slope } \\
\text { coefficient } \\
10^{-3}\end{array}$ & $\begin{array}{c}95 \% \\
\text { confidence } \\
\text { interval } \\
10^{-3}\end{array}$ & Intercept & $\begin{array}{c}\text { Slope } \\
\text { coefficient } \\
10^{-3}\end{array}$ & $\begin{array}{c}95 \% \\
\text { confidence } \\
\text { interval } \\
10^{-3}\end{array}$ \\
\hline $\begin{array}{l}1 \\
2 \\
3 \\
4 \\
5 \\
6\end{array}$ & $\begin{array}{l}50 \\
65 \\
68 \\
72 \\
62 \\
71\end{array}$ & $\begin{array}{l}-1.6 \\
-1.7 \\
-3.1 \\
-1.9 \\
-1.7 \\
-1.0\end{array}$ & $\begin{array}{l}-1.7--1.4 \\
-1.8--1.5 \\
-3.5--2.7 \\
-2.2--1.6 \\
-1.9--1.5 \\
-1.3--0.8\end{array}$ & $\begin{array}{r}234 \\
272 \\
86 \\
113 \\
143 \\
39\end{array}$ & $\begin{array}{l}27 \\
14 \\
17 \\
16 \\
5.6 \\
2.0\end{array}$ & $\begin{array}{c}25-30 \\
11-17 \\
15-18 \\
14-18 \\
4.0-7.2 \\
1.6-2.3\end{array}$ \\
\hline
\end{tabular}

Table 2. Regression analysis of the mean power frequency (MPF) (Hz) and root-mean square (rms) amplitudes ( $\mu \mathrm{V}$ ), versus time (s), for the infraspinatus muscle. The intercept, slope, and $95 \%$ confidence interval for the slope coefficient are illustrated for each subject.

\begin{tabular}{|c|c|c|c|c|c|c|}
\hline \multirow[b]{2}{*}{ Subject } & \multicolumn{3}{|c|}{ MPF } & \multicolumn{3}{|c|}{$\mathrm{rms}$} \\
\hline & Intercept & $\begin{array}{c}\text { Slope } \\
\text { coefficient } \\
10^{-3}\end{array}$ & $\begin{array}{c}95 \% \\
\text { confidence } \\
\text { interval } \\
10^{-3}\end{array}$ & Intercept & $\begin{array}{c}\text { Slope } \\
\text { coefficient } \\
10^{-3}\end{array}$ & $\begin{array}{c}95 \% \\
\text { confidence } \\
\text { interval } \\
10^{-3}\end{array}$ \\
\hline $\begin{array}{l}1 \\
2 \\
3 \\
4 \\
5 \\
6\end{array}$ & $\begin{array}{l}66 \\
68 \\
79 \\
85 \\
68 \\
81\end{array}$ & $\begin{array}{l}-3.3 \\
-3.2 \\
-1.1 \\
-2.9 \\
-3.5 \\
-2.9\end{array}$ & $\begin{array}{l}-3.4--3.2 \\
-3.4--3.1 \\
-1.3--0.8 \\
-3.3--2.6 \\
-3.8--3.3 \\
-3.1--2.8\end{array}$ & $\begin{array}{r}64 \\
106 \\
52 \\
71 \\
96 \\
30\end{array}$ & $\begin{array}{r}1.5 \\
-1.0 \\
-0.4 \\
1.8 \\
-0.2 \\
-0.1\end{array}$ & $\begin{array}{r}9.7-2.1 \\
-2.0-0.1 \\
-0.9-0.2 \\
0.9-2.7 \\
-1.1-0.7 \\
-0.4-0.1\end{array}$ \\
\hline
\end{tabular}

Table 3. Regression analysis of the mean power frequency (MPF) (Hz) and root-mean-square (rms) amplitudes ( $\mu \mathrm{V})$, versus time (s), for the cervical portion of the descending trapezius muscle. The intercept, slope, and $95 \%$ confidence interval for the slope coefficient are illustrated for each subject.

\begin{tabular}{|c|c|c|c|c|c|c|}
\hline \multirow[b]{2}{*}{ Subject } & \multicolumn{3}{|c|}{ MPF } & \multicolumn{3}{|c|}{$\mathrm{rms}$} \\
\hline & Intercept & $\begin{array}{c}\text { Siope } \\
\text { coefficient } \\
10^{-3}\end{array}$ & $\begin{array}{c}95 \% \\
\text { confidence } \\
\text { interval } \\
10^{-3}\end{array}$ & Intercept & $\begin{array}{c}\text { Slope } \\
\text { coefficient } \\
10^{-3}\end{array}$ & $\begin{array}{c}95 \% \\
\text { confidence } \\
\text { interval } \\
10^{-3}\end{array}$ \\
\hline $\begin{array}{l}1 \\
2 \\
3 \\
4 \\
5 \\
6\end{array}$ & $\begin{array}{r}80 \\
79 \\
115 \\
110 \\
79 \\
83\end{array}$ & $\begin{array}{l}-2.5 \\
-0.7 \\
-6.1 \\
-0.8 \\
-0.3 \\
-0.4\end{array}$ & $\begin{array}{l}-2.7--2.3 \\
-0.9--0.5 \\
-6.6--5.6 \\
-1.2-0.3 \\
-0.5--0.1 \\
-0.8--0.1\end{array}$ & $\begin{array}{c}19 \\
20 \\
14 \\
4.6 \\
14 \\
8.3\end{array}$ & $\begin{array}{c}2.5 \\
-0.3 \\
3.5 \\
0.6 \\
-0.02 \\
0.2\end{array}$ & $\begin{array}{c}2.3-2.7 \\
-0.5--0.1 \\
3.2-3.9 \\
0.5-0.6 \\
-0.1-0.1 \\
0.2-0.3\end{array}$ \\
\hline
\end{tabular}


negative for four subjects and positive for two (table 2 ). For the cervical portion of the descending trapezius muscle negative slopes for the MPF and positive slopes for the rms were determined for four subjects. For two subjects the slopes of the rms were negative in combination with negative slopes of the MPF (table 3).

\section{Muscle fatigue during the 5-min periods}

Regression analysis of the EMG amplitude and frequency for each 5-min period during the $1 \mathrm{~h}$ of work showed incidences of EMG signs of fatigue in all three muscles. The patterns of the EMG signs of fatigue were

A) The bateral portion of the descending trapezius muscle

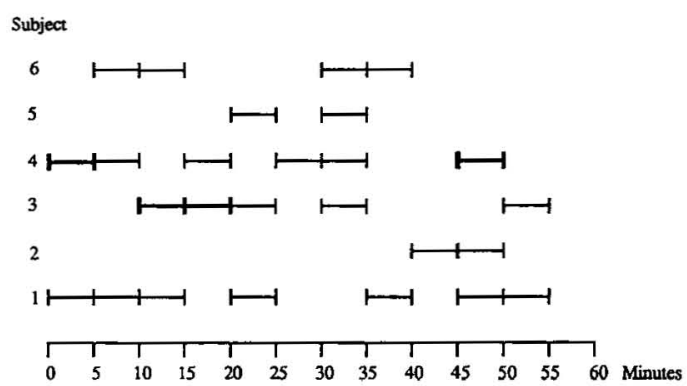

B) The infraspinatus muscle

Subject

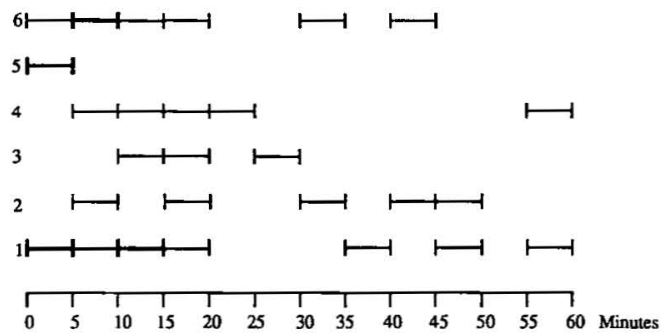

C) The cervical portion of the descending trapezius muscle

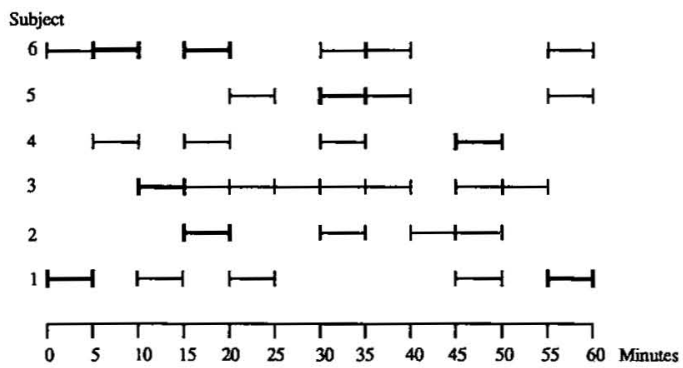

Figure 2. Patterns of electromyographic incidents of muscle fatigue defined as an increase in root-mean-square (rms) amplitude with a simultaneous decrease in mean power frequency (MPF) in 5-min periods during the 60-min work task. Fiveminute periods with a significant $(P<0.05)$ increase in rms and decrease in MPF are indicated with a bold line. Blank spaces indicate no signs of fatigue as determined by the MPF and rms relationships. different between muscles and between subjects, as seen in figure 2. The decrease in MPF and increase in rms for each subject are illustrated for the 5-min periods in figure 3 .

\section{Rating of perceived exertion}

Starting from no exertion at all before the work, the mean RPE values reached 11 (light) after $5 \mathrm{~min}, 13.5$ (somewhat hard) after $35 \mathrm{~min}$, and 14 (between somewhat hard and hard) after $60 \mathrm{~min}$. A negative correlation $(\mathrm{r}=-0.59, \mathrm{~N}=12, \mathrm{P}<0.001)$ was found between the means of the MPF and the RPE, and a positive correlation $(r=0.35, \mathrm{~N}=12, \mathrm{P}<0.01)$ was seen between the means of the rms and the RPE on the basis of calculations from the 5-min periods.
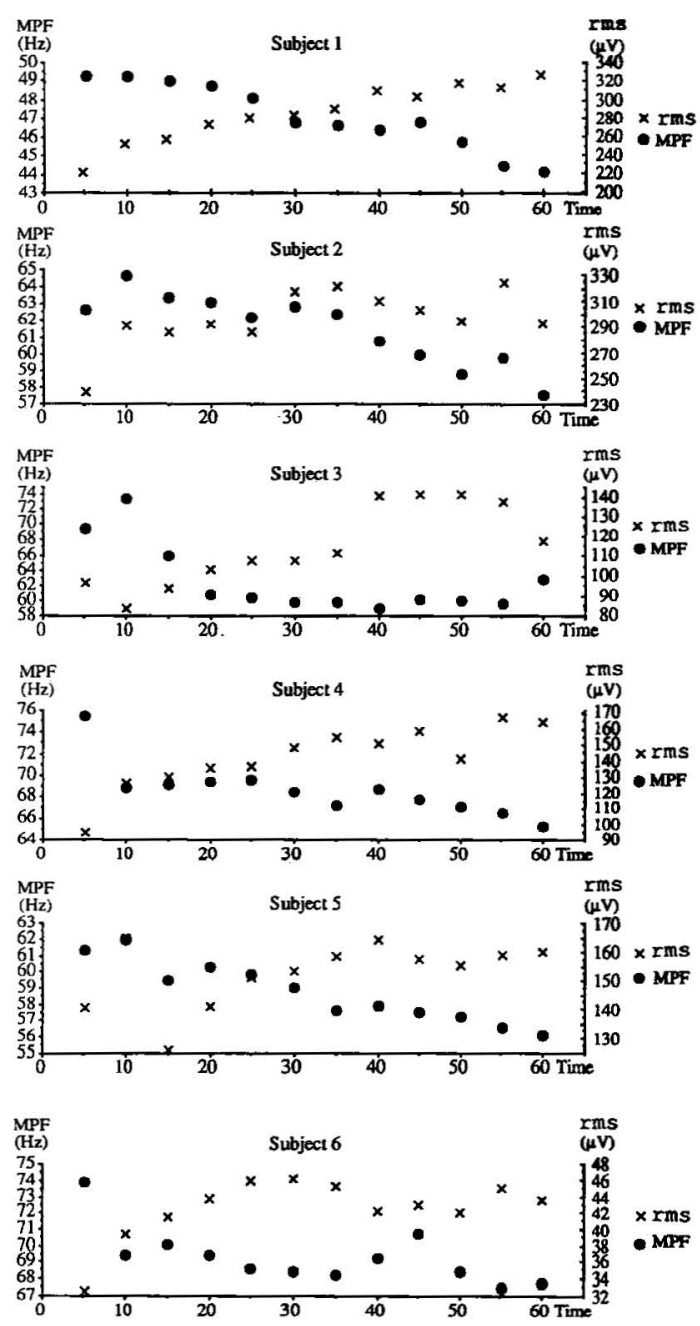

Figure 3. Means for mean power frequency (MPF) and the rootmean-square (rms) amplitudes in 5-min periods for each subject. 


\section{Discussion}

Despite the dynamic character of the work task EMG signs of fatigue developed in the lateral portion of the descending trapezius muscle in the analysis over the entire work period for all of the subjects. It has been suggested (21) that a decrease in MPF in electromyography should be greater than $8 \%$ of the initial values to be considered significant when joint angles of the arm are changing, as in dynamic muscle activity. Calculations based on the regression equation for the whole work period showed changes in MPF exceeding $8 \%$ in five of the six subjects in the lateral portion of the descending trapezius muscle. In repetitive work at a pillar drill (8), in welding work (3), in simulated work tasks in different work postures (5), and in elevated arm positions (6), EMG signs of fatigue have also been found in the descending trapezius muscle.

The cervical portion of the upper trapezius muscle had a different activity pattern than the lateral portion. The static load was higher in the cervical portion although signs of fatigue were not found for all of the subjects. The difference in muscle load could be explained by the measurement procedure used for the RVC, which was probably more optimal for the lateral than for the cervical portion of the trapezius muscle. In addition in several EMG studies different functions for the different portions of the descending trapezius muscle have been suggested (22-24). Another explanation for the different activity pattern could be that the fiber type composition is different for the upper and lower portions of the descending trapezius muscle. The lower part has a predominance of type I fibers and is suggested to have a postural function, and the upper part is composed mostly of type II fibers with a main function of head motor control and response to postural sway (25).

For the infraspinatus muscle signs of fatigue over the entire work period were found in two subjects. This result was, to a great extent, consistent with those seen in work on a pillar drill, where no signs of fatigue were found in the infraspinatus muscle (8). Although this muscle is always activated in the flexion and abduction of the humerus and it forms a functional group together with the subscapular and teres minor muscles (26), it did not seem to be as susceptible to fatigue in this study as the descending trapezius muscle did.

Incidences of muscle fatigue were found in the myoelectric signal in the 5 -min periods. The number of intervals with fatigue differed between subjects and between muscles. The interindividual differences are consistent with the results of other studies in which much interindividual variability in muscle activity was found in self-paced work tasks $(27,28)$. In addition standardized machine-paced work at a packing machine produced great interindividual variability in trapezius muscle activity (29). The variability of fatigue incidences within the same muscle and between mus- cles could be due to fatigue of certain motor units. While these motor units are recovering from fatigue, other units in the same muscle or another muscle could take over their function. This process leads to a constant change of motor units in order to maintain muscle activity. A regular change in EMG activity between the rectus femoris and vastus lateralis in a fatiguing prolonged static contraction in the quadriceps muscle has been reported (30). The variable fatigue patterns could also be explained by an afferent flow from fatigued muscle fibers to the central nervous system regulating the recruitment of motor units. It has been suggested that EMG changes during sustained maximal voluntary contractions are attributable to a progressive reduction in the neural drive emanating from the central nervous system and not from failure of peripheral transmission in the muscle (31). In addition a changed position within the range of motion for the subjects could possibly explain the variable pattern of muscle fatigue. No change in work posture was however observed during the experiment. All of the operators kept the predetermined speed, and the work output was the same for all of them.

In this study a continuous increase in the RPE with the same work output could indicate a fatiguing process caused by high monotony in the work task, lack of visual and mental stimulation, and a high work load resulting in local muscle fatigue. Thus the RPE values given in the current study support our EMG findings of fatigue. The RPE scale integrates information from peripheral muscles and joints and cardiovascular and respiratory functions from the central nervous system and evaluates how the subjective intensity varies with physical intensity (20). The increase in the mean ratings from 11 to 14 between minutes 5 and 60 does not seem extensive, but a fatiguing process is, on the other hand, supported by the perception of exertion and discomfort reported by the subjects for the right arm. The variations in muscle activity, measured as the difference between peak and static loads, were $27 \%$ for the lateral portion of the descending trapezius muscle and $20 \%$ for the cervical portion. The trapezius muscle activity in this repetitive work simulation task could thus be regarded as dynamic muscle activity with high load levels. The infraspinatus muscle showed a difference of $43 \%$ between the static and peak load, a finding which also indicated dynamic muscle function.

Although there was dynamic muscle activity, signs of muscle fatigue and an increase in the perception of discomfort developed. The cycle time, $1.46 \mathrm{~s}$, was probably too short to allow relaxation of the shoulder muscles when the arm was lowered to the table and the cylinder released. A slower work pace, integrated pauses, or a redesign of the workstation requiring less shoulder flexion could possibly have prevented the development of fatigue. Of interest however is that a fatiguing process developed in muscles and in the perception of discomfort at a work pace which is com- 
mon in Sweden. Work pace is definitely one factor of interest in the prevention of muscle fatigue and discomfort at work.

This study was a laboratory study with a controlled experimental design and a predetermined work pace. The results may therefore not be comparable to ordinary work conditions where pauses and breaks are integrated into the work. A laboratory study in which as many surrounding factors as possible could be kept constant was however considered to be the most suitable. The choice of physiotherapy students as subjects for this work simulation task was made because of the importance of skill acquisition in the performance. Even if all of them acquired skill easily during the training period, further skill development during weeks of training might possibly have reduced the muscle tension and thus also the development of muscle fatigue during the work task. Older subjects or subjects with musculoskeletal problems would presumably have had an even greater variation in the EMG parameters.

In conclusion we found that fatigue and a perception of discomfort developed in shoulder muscles during $1 \mathrm{~h}$ of highly standardized repetitive arm work, which was paced according to MTM-110. The muscle activity pattern with signs of muscle fatigue showed much variability between subjects and between muscles. It is therefore suggested that dynamic work movements do not protect the muscles in the shoulders and neck from fatiguing processes in highly repetitive work with short cycle times.

\section{Acknowledgments}

The Swedish Work Environment fund is gratefully acknowledged for its financial support (project number 86-1487).

The authors are also indebted to Mr U Hammarström for his skillful EMG analysis.

\section{References}

1. Luopajärvi T, Kuorinka I, Virolainen M, Holmberg M. Prevalence of tenosynovitis and other injuries of the upper extremities in repetitive work. Scand J Work Environ Health 1979;5 suppl 3:48-55.

2. Kvarnström S. Occurrence of musculoskeletal disorders in a manufacturing industry with special attention to occupational shoulder disorders. Scand J Rehabil Med Suppl 1983;8:1-114.

3. Kadefors R, Petersén I, Herberts P. Muscular reaction to welding work: an electromyographic investigation. Ergonomics 1976;19:543-58.

4. Lindström L, Kadefors R, Petersén I. An electromyographic index for localized muscle fatigue. J Appl Physiol Respir Environ Exercise Physiol 1977;43:750—4.

5. Herberts $\mathrm{P}$, Kadefors R, Broman $\mathrm{H}$. Arm positioning in manual tasks: an electromyographic study of localized muscle fatigue. Ergonomics 1980;23:655-65.

6. Hagberg M. Work load and fatigue in repetitive arm elevations. Ergonomics 1981;24:543-55.

7. Hagberg M. Electromyographic signs of shoulder mus- cular fatigue in two elevated arm positions. Am J Phys Med Rehabil 1981;60:111-21.

8. Christensen H. Muscle activity and fatigue in the shoulder muscles during repetitive work: an electromyographic study. Eur J Appl Physiol 1986;54:596-601.

9. Christensen H. Muscle activity and fatigue in the shoulder muscles of assembly-plant employees. Scand J Work Environ Health 1986;12:582-7.

10. Baidya KN, Stevenson MG. Local muscle fatigue in repetitive work. Ergonomics 1988;31:227-39.

11. Chaffin DB, Andersson GBJ. Methods of classifying and evaluating manual work. In: Chaffin DB, Andersson GBJ, ed. Occupational biomechanics. New York, Chichester, Brisbane, Toronto, Singapore: John Wiley \& Sons, 1984:233-62.

12. Magnusson K. The development of MTM-2, MTM V and MTM-3. J Methods-Time Meas 1972;17:11-23.

13. Hagberg M, Sundelin G. Discomfort and load on the upper trapezius muscle when operating a word processor. Ergonomics 1986;29:1637-45.

14. Sundelin G, Hagberg M. The effects of different pause types on neck and shoulder EMG activity during VDU work. Ergonomics 1989;32:527-37.

15. Jonsson B. Muscular fatigue and endurance basic research and ergonomic applications. In: Kumamoto $\mathbf{M}$, ed. Neural and mechanical control of movement. Kyoto: Yamaguchi Shoten, 1984:64-76.

16. Kadefors R, Kaiser E, Petersén I. Dynamic spectrum analysis of myopotentials with special reference to muscle fatigue. Electromyography $1968 ; 2: 39-74$.

17. Basmajian JV, de Luca CJ. Muscle fatigue and timedependent parameters of the surface EMG signal. In: Basmajian JV, de Luca CJ, ed. Muscles alive: their function revealed by electromyography. Baltimore, London, Los Angeles, Sydney: Williams and Wilkins, 1985:20122.

18. Ericson BE, Hagberg M. EMG-signal level versus external force: a methodological study on computer aided analysis. In: Asmussen E, Jörgensen K, ed. Biomechanics VI-A. Baltimore, MD: University Park Press, 1978:251-5.

19. Hagberg M. The amplitude distribution of surface EMG in static and intermittent static muscular performance. Eur J Appl Physiol 1979;40:265-72.

20. Borg G. Psychophysical scaling with applications in physical work and the perception of exertion. Scand J Work Environ Health 1990;16 suppl 1:55-8.

21. Öberg T, Sandsjö L, Kadefors R. Electromyogram mean power frequency in non-fatigued trapezius muscle. Eur J Appl Physiol 1990;61:362-9.

22. Mathiassen SE, Winkel J. Electromyographic activity in the shoulder-neck region according to arm position and glenohumeral torque. Eur J Appl Physiol 1990;61: $370-9$.

23. Westgaard R. Measurement and evaluation of postural load in occupational work situations. Eur J Appl Physiol 1988;57:291-304.

24. Schüldt K, Harms-Ringdahl K. Activity levels during isometric test contractions of neck and shoulder muscles. Scand J Rehabil Med 1988;20:117-27.

25. Lindman R, Eriksson A, Thornell L-E. Fiber type composition of the human female trapezius muscle: enzymehistochemical characteristics. Am J Anat 1991;190: 385-92.

26. Inman VT, Sauders JBCM, Abbott LC. Observations on the function of the shoulder joint. J Bone Joint Surg $1944 ; 26: 1-30$.

27. Aarås A, Westgaard RH. Further studies of postural load and musculoskeletal injuries of workers at an electromechanical assembly plant. Appl Ergon 1987;18: 211-19.

28. Kilbom $\AA$, Persson J. Work technique and its consequences for musculoskeletal disorders. Ergonomics 1987; 
30:273-9.

29. Veiersted KB, Westgaard RH, Andersen P. Pattern of muscle activity during stereotyped work and its relation to muscle pain. Int Arch Occup Environ Health 1990; $62: 31-41$.

30. Sjøgaard G, Kiens B, Jørgensen K, Saltin B. Intramuscular pressure, EMG and blood flow during low-level prolonged static contraction in man. Acta Physiol Scand
1986;128:475-84.

31. Bigland-Ritchie B, Johansson R, Lippold OCJ, Woods JJ. Contractile speed and EMG changes during fatigue of sustained maximal voluntary contractions. J Neurophysiol 1983;50:313-24.

Received for publication: 5 November 1991 